\title{
CONSTRUINDO MOVIMENTOS: UMA CONVERSA EM TEMPOS DE PANDEMIA
}

Building movements: a conversation in times of pandemic

Isabella Brunini Simões PADULA

Faculdade de Educação

Universidade Estadual de Campinas

Campinas, Brasil

isabellabsp@gmail.com

https://orcid.org/0000-0001-5437-4057

A lista completa com informações dos autores está no final do artigo

ANGELA DAVIS E

NAOMI KLEIN

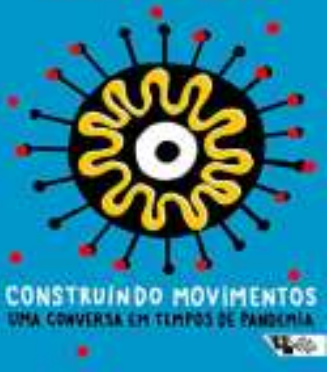

DAVIS, Angela; KLEIN, Naomi. Construindo movimentos: uma conversa em tempos de pandemia. Tradução Leonardo Marins. São Paulo: Boitempo, 2020. 


\section{RESUMO}

O livro aqui resenhado baseia-se em uma conversa on-line organizada pelo movimento Rising Majority, e protagonizada por Angela Davis e Naomi Klein. O debate teve como foco a reflexão sobre a atual pandemia do coronavírus, sua origem e impactos sociais, além de estratégias de resposta coletiva à crise. Participaram também as ativistas e líderes do Rising Majority Thenjiwe McHarris, Cindy Wiesner, Maurice Mitchell e Loan Tran. Dentre as várias reflexões propostas durante o encontro, as debatedoras colocam a relação entre pandemia, capitalismo e racismo no centro de suas análises. A discussão também nos ajuda a pensar a realidade da Educação Infantil no Brasil.

PALAVRAS-ChAVE: Pandemia. Crise. Coronavírus. Capitalismo. Racismo.

\section{ABSTRACT}

The book reviewed is based on an online conversation organized by the Rising Majority movement, with the participation of Angela Davis and Naomi Klein. The debate centralized the reflection on the current coronavirus pandemic, its origin and social impacts, as well the possible strategies to respond to the crisis. The Rising Majority leaders Thenjiwe McHarris, Cindy Wiesner, Maurice Mitchell and Loan Tran also participated in the debate. Among the several reflections raised in the meeting, the debaters put the relationship between pandemic, capitalism and racism at the center of their analysis. The discussion also helps us to think about the reality of early childhood education in Brazil.

KEYWORDS: Pandemic. Crisis. Coronavirus. Capitalism. Racism.

\section{RESENHA}

Tendo como base um debate on-line protagonizado pelas pensadoras feministas Angela Davis e Naomi Klein, o volume a ser discutido integra a coleção "Pandemia Capital", veiculada pela Editora Boitempo. Trata-se de uma série de produções curtas que têm como foco a crise provocada pelo coronavírus e as consequências dela oriundas, sejam elas vistas sob o ponto de vista social, econômico ou de outras esferas importantes para a reflexão sobre a pandemia.

Davis é filósofa, ativista e símbolo da luta pelos direitos civis, professora na Universidade da Califórnia e uma das mais importantes pensadoras contemporâneas. Em Mulheres, Raça e Classe (2016), uma de suas principais obras, traduzida e publicada no Brasil, Davis analisa a forma como se estruturam as opressões na sociedade capitalista, focalizando a condição das mulheres negras que vivenciam, simultaneamente, as opressões de gênero, raça e classe. Atualmente, uma das principais questões discutidas por Davis tem sido a realidade perversa do encarceramento em massa da população negra, tendo se tornado também uma das principais figuras na defesa pelo abolicionismo penal.

Klein, por sua vez, é uma reconhecida jornalista, ativista e escritora best-seller canadense. Seus textos publicados em importantes veículos de comunicação, como The Intercept e The Guardian, além de seus livros, abordam temas como política, o capitalismo e suas crises e as mudanças climáticas. Em Não basta dizer não (2017), seu último livro traduzido e publicado no Brasil, Klein analisa conjuntura que levou à 
ascensão de Donald Trump à presidência dos Estados Unidos, os perigos decorrentes dessa eleição e as estratégias de resistência a esse governo.

O encontro entre as duas pensadoras aconteceu em 2 de abril de 2020 e foi planejado pela Rising Majority, uma aliança de movimentos de esquerda e anti-racistas com o objetivo de desenvolver e compartilhar estratégias coletivas para o fortalecimento da esquerda radical anti-racista ${ }^{1}$. A conversa foi mediada por Thenjiwe McHarris, liderança do Rising Majority, e, em um primeiro momento, girou em torno do diálogo entre Davis e Klein, que compartilharam suas visões sobre a pandemia e o que ela nos revela. Depois, se juntam Cindy Wiesner, Maurice Mitchell e Loan Tran, todos ativistas em diferentes movimentos sociais.

Um dos principais direcionamentos da conversa diz respeito à forma como o capitalismo, combinado à perversidade do racismo estrutural, deixou grupos sociais em desvantagem no combate à doença que atinge, no mundo todo, sobretudo as pessoas em condições de vulnerabilidade, a população negra e as mulheres trabalhadoras. Dividida em blocos de perguntas e respostas, a discussão também explorou formas criativas de sair desta crise causada pelo capitalismo e escancarada pela pandemia da COVID-19 (Corona Virus Disease 2019).

Thenjiwe McHarris inicia a conversa afirmando que o mundo não enfrenta hoje apenas as consequências do vírus, mas também os ataques incitados pelo "capitalismo racial" (DAVIS; KLEIN, 2020, p. 7). O uso desta expressão demonstra a ligação intrínseca entre capitalismo e racismo, os quais se alimentam reciprocamente. $O$ triunfo do capitalismo é amplamente dependente das hierarquias criadas pelo racismo, e o racismo é também sustentado pelos interesses capitalistas. Mc Harris aponta, então, a exigência do momento por perspectivas transformadoras, e convida Davis e Klein a compartilharem suas visões sobre o momento atual e como ele evidencia as deficiências do capitalismo.

Naomi Klein responde salientando como nossa vontade por conexões pessoais parece agigantar-se em um momento que exige isolamento e nos priva da companhia uns dos outros. Porém, ela lembra que a quarentena é um privilégio daqueles que não precisam sair para trabalhar, ou mesmo que possuem uma casa para isolar-se. De forma objetiva, Klein inicia afirmando, com todas as letras, o desastre que é o capitalismo. Segundo a pensadora, a crise do coronavírus é causada por este sistema, e configura uma manifestação do que ela chamou "guerra contra a natureza" (DAVIS;

1 Informações coletadas no site oficial do The Rising Majority. Disponível em: <https://therisingmajority.com/about-us/>. Acesso em: 15 nov. 2020. 
KLEIN, 2020, p. 8). Assim, para Klein, o sistema econômico sobrepõe o lucro à vida e cria as condições para o aprofundamento da crise e a propagação descontrolada do vírus, como a precarização do trabalho na área da saúde, do cuidado e do setor de serviços, e a ineficiência dos sistemas de saúde em proverem equipamentos de segurança. Klein expõe como governos ao redor do mundo justificam medidas em nome da crise do coronavírus, quando na verdade estão priorizando seus próprios interesses. É o caso da suspensão de regulamentações ambientais na China e nos Estados Unidos, e de artifícios autoritários usados por governos como o de Trump nos Estados Unidos, e de Jair Bolsonaro no Brasil.

Já Angela Davis inicia sua fala enfatizando a importância do fortalecimento através das conexões globais, e declarando sua preocupação com aquelas populações mais vulneráveis ao redor do mundo. Ao ser convidada a falar sobre a pandemia a partir de um ponto de vista abolicionista, Davis defende o desencarceramento como estratégia de saúde coletiva. Ela argumenta ainda que a quarentena doméstica como uma medida de enfrentamento à transmissão do vírus contrasta com a realidade de milhões de pessoas que não possuem um espaço de abrigo, inclusive muitas libertadas das prisões. Assim, para além do desencarceramento, para Davis é preciso pensar também no oferecimento de moradia e alimentação gratuitas.

Em um segundo momento deste diálogo entre as duas pensadoras contemporâneas, McHarris pede para Klein apresentar aquilo que ela vê como possibilidade de ação no contexto da pandemia. Para basear sua fala, a jornalista começa considerando a indispensabilidade de reconhecer a situação de pandemia como uma emergência. Segundo Klein, o despreparo no enfretamento ao coronavírus provém da relativização da crise, trazendo à tona visões perversas, como a de que "(...) pessoas idosas e doentes deveriam morrer silenciosamente em nome do mercado de ações" (DAVIS; KLEIN, 2020, p. 14).

Além disso, se apoiando nas ideias de Milton Friedman, Naomi Klein enxerga a pandemia como uma crise que, produzida pelo capitalismo e reveladora de todas as injustiças deste sistema, abre espaço para a reação da esquerda. Ela compara o momento atual com a crise econômica de 2008, mas pondera as semelhanças quando pensa na reação da esquerda. Segundo Klein, naquele período não foram apresentadas saídas radicais e transformadoras à crise, o que precisa acontecer agora. A inspiração necessária para a construção desta resposta está, para a jornalista, na força da classe trabalhadora que atua na linha de frente do combate à COVID-19. Com o trabalho quase sempre precarizado, estes trabalhadores se levantam agora para mostrar a 
essencialidade de suas funções, e é nessa força que Klein espera buscar inspiração, e são esses trabalhadores que precisam ser apoiados acima de tudo.

Angela Davis finaliza este bloco do debate reafirmando mais uma vez a culpa do capitalismo global pelas tragédias da pandemia, e a forma como esta crise revela também as faces do capitalismo racial, iniciando pelo racismo dirigido aos asiáticos nos Estados Unidos, e podemos dizer que também aqui no Brasil. Segundo a filósofa, a falha na entrega dos kits de teste para bairros negros é outro exemplo do racismo estrutural que atinge as instituições, e que deve ser combatido com urgência. A reação ao racismo perpassa, obrigatoriamente, a organização feminista. Para Davis, todas as questões a serem combatidas, como a falta de moradia e o desencarceramento, são questões feministas, devendo ter em mente que muitas das pessoas no foco da crise da COVID19 são mulheres negras, pobres, trans, moradoras do sul global. Deste modo, Davis aponta que a resposta à crise deve partir da solidariedade internacional, o que exige a superação de uma "ilusão autocentrada nos EUA" (DAVIS; KLEIN, 2020, p. 19). Ela termina chamando a atenção para mais uma face cruel da pandemia: o fato de que muitas crianças e mulheres estão sendo obrigadas a permanecerem trancadas com seus agressores em casa, o que deve ser levado em conta na elaboração de uma resposta à crise.

Em um segundo momento da conversa, a mediadora Thenjiwe McHarris convida os outros participantes, lideranças na Rising Majority, a entrarem na conversa, iniciando por Cindy Wiesner. A ativista começa afirmando a chance que a crise da COVID-19 dá, à direita e à esquerda, de agir. No caso de uma falha na reação na esquerda, Wiesner acredita que o autoritarismo e o fascismo representarão o futuro. Segundo ela, não basta pedir apenas pelos itens obrigatórios no combate à doença, como as máscaras e ventiladores, mas devem ser exigidos também pontos como a desmilitarização, o cessar de invasões territoriais, a priorização de pessoas e não de empresas, a solidariedade com populações de regiões como Irã, Palestina e Venezuela, países que sofrem sanções dos Estados Unidos. A inspiração, segundo Wiesner, deve vir dos movimentos ao redor do mundo que apresentam outros caminhos para além do capitalismo: o movimento feminista; as alternativas apontadas pelos povos indígenas; a produção de alimentos pelos pequenos agricultores. Segundo Wiesner, precisamos "(...) estar capacitados para falar o que queremos, não apenas o que rejeitamos (...)" (DAVIS; KLEIN, 2020, p. 22).

Depois, Maurice Mitchell é convidado a falar sobre a relação entre as eleições nos Estados Unidos e a pandemia atual. Segundo Mitchell, os impactos da crise na ação dos movimentos organizados que atuam durante as eleições são grandes. Todas as 
atividades que eram possíveis através dos relacionamentos "cara a cara, porta a porta" (DAVIS; KLEIN, 2020, p. 23) - como comícios e campanhas nas comunidades - devem agora ser repensadas, já que a pandemia exige das pessoas o isolamento doméstico. Segundo o ativista, é preciso adaptação, o que já está sendo feito através do uso de mídias sociais, SMS, entre outras ferramentas para continuar criando conexões. Outro aspecto importante levantado por Mitchell é a necessidade de pessoas dentro dos movimentos sociais concorrerem a cargos políticos, para representarem os interesses da classe trabalhadora que estão em desacordo com os interesses empresariais. Ele reitera que é preciso garantir que a extrema direita não aproveite da crise para atacar a democracia, pois certamente os "autoritários de todo o mundo seguirão uns aos outros." (DAVIS; KLEIN, 2020, p. 26).

Para encerrar a participação dos ativistas no debate, Loan Tran é questionado sobre a xenofobia e o racismo contra os asiáticos, fomentados durante esta crise. Tran inicia seu argumento apontando para a ignorância do discurso antichinês, proferido por Trump, que utiliza expressões como "vírus chinês". De acordo com o ativista, esse discurso baseia políticas sociais e econômicas desastrosas, e desconsidera a realidade do povo chinês que também morre com a pandemia, que é "[...] vítima de guerras imperialistas, vítima de desastres climáticos e extrativismo predatório, vítima de ocupação e neocolonialismo." (DAVIS; KLEIN, 2020, p. 27). O uso deste discurso xenófobo revela que a crise da pandemia é, na realidade, a crise do capitalismo racial, que desde sempre atacou muçulmanos, imigrantes, pessoas negras e indígenas, e que agora culpa com mais força o povo asiático, em uma armadilha para tirar de mira os verdadeiros culpados.

Na última etapa do debate, McHarris convida novamente Angela Davis e Naomi Klein a darem suas palavras finais. Klein inicia sua fala trazendo sugestões para a organização da resposta à crise: a transformação das pequenas empresas, que vivem dificuldades com o fechamento dos estabelecimentos, em cooperativas, pois isso evita o monopólio de grandes empresas; o uso de alternativas digitais que vá além daquelas controladas pelas grandes empresas; a valorização do trabalho de cuidado com as pessoas e com a natureza; e possivelmente até mesmo uma greve geral. Ela finaliza sua fala ressaltando a importância de nos aproximarmos e conectarmos, mesmo em tempos de isolamentos, pois só assim é possível construir uma resistência.

Davis conclui sua participação insistindo na imprescindibilidade das conversas globais, que envolvam também pessoas de lugares como África, América do Sul, e Índia. Neste momento, ela demonstra preocupação com a situação vivida pelo Brasil, que ela 
considera ainda pior que a dos Estados Unidos, frisando a semelhança entre os presidentes de ambos os países. Para a filósofa, "podemos encontrar em lugares como - Brasil e a África do sul vozes que almejem sair criativamente desta crise" (DAVIS; KLEIN, 2020, p. 32). Ela termina afirmando a limitação do modelo "estado-nação", e a pertinência de uma movimentação internacional que caminhe no sentido de superar o "monstro capitalista em direção a um futuro melhor" (DAVIS; KLEIN, 2020, p. 33).

Desta forma, considero que a leitura do livro ajuda a pensar as origens desta crise atual, a qual extrapola os limites da saúde e escancara as limitações de um sistema que ataca especialmente a população negra, indígena, pobre, mulheres, crianças, imigrantes, asiáticos. A contribuição das duas pensadoras contemporâneas, Angela Davis e Naomi Klein, nos ajudam a pensar em alternativas de resposta à crise, as quais devem centralizar as vivências globais das diferentes populações ao redor do mundo, e as condições da classe trabalhadora que atua na linha de frente do combate ao coronavírus. Para ambas, assim como para os líderes do Rising Majority que participaram da conversa, a saída à crise não perpassa apenas a superação da pandemia, mas também a superação do capitalismo racial.

No Brasil, as falhas do Estado em combater a pandemia têm afetado de forma mais agressiva as periferias do país, a população negra e indígena, a classe trabalhadora, entre outros grupos sociais vulnerabilizados. Esta desigualdade, que não nasceu da pandemia, mas foi por ela escancarada, precisa ser considerada também quando pensamos a realidade da Educação Infantil brasileira no contexto pandêmico: quem são as crianças mais afetadas pela suspensão das atividades nas creches e préescolas? Para além disso, quais seriam as famílias mais vulneráveis com um possível retorno das atividades pedagógicas presenciais? Pensando as atividades EaD como totalmente insuficientes no contexto da Educação Infantil, que prevê a interação e a brincadeira como eixos estruturantes do trabalho pedagógico, como estão sendo pensadas estas atividades? Quais crianças não conseguem acompanhar as propostas que, muitas vezes, pressupõe a todas as crianças condições como acesso à internet, pais e mães alfabetizadas, ambientes domésticos tranquilos, posse de aparelhos eletrônicos, dentre outras? Considerando que a escola representa um ambiente seguro e com profissionais prontas para perceber e denunciar violências, como proteger as crianças que estão isoladas em casa com seus agressores, e longe destes espaços?

As instituições de Educação Infantil também estão na sociedade e por isso também reproduzem as desigualdades de raça, gênero e classe. Pensar a Educação Infantil hoje precisa perpassar a reflexão sobre a pandemia no Brasil, e a forma como 
esta realidade estreita as desigualdades e atinge, de forma desproporcional, os diferentes grupos sociais.

\section{REFERÊNCIAS}

DAVIS, Angela. Mulheres, raça e classe. São Paulo: Boitempo Editorial, 2016.

KLEIN, Naomi. Não basta dizer não. Rio de Janeiro: Bertrand Brasil, 2017.

\section{NOTAS}

TÍTULO DA OBRA

CONSTRUINDO MOVIMENTOS: UMA CONVERSA EM TEMPOS DE PANDEMIA

Building movements: a conversation in times of pandemic

Isabella Brunini Simões Padula

Mestranda em Educação

Universidade Estadual de Campinas

Faculdade de Educação

Campinas, Brasil

isabellabsp@gmail.com

Ohttps://orcid.org/0000-0001-5437-4057

Endereço de correspondência do principal autor

Faculdade de Educação, Unicamp, Av. Bertrand Russel, 801, 13083-865, Campinas - SP, Brasil.

\section{AGRADECIMENTOS}

Não se aplica

CONTRIBUIÇÃO DE AUTORIA

Concepção e elaboração do manuscrito: I. B S. Padula

Coleta de dados: I. B S. Padula

Análise de dados: I. B S. Padula

Discussão dos resultados: I. B S. Padula

Revisão e aprovação: I. B S. Padula

CONJUNTO DE DADOS DE PESQUISA

Todo o conjunto de dados que dá suporte aos resultados deste estudo foi publicado no próprio artigo.

\section{FINANCIAMENTO}

CNPq financia a minha pesquisa de mestrado - 830506/1999-3

\section{CONSENTIMENTO DE USO DE IMAGEM}

Não se aplica

\section{APROVAÇÃO DE COMITÊ DE ÉTICA EM PESQUISA \\ Não se aplica}

\section{CONFLITO DE INTERESSES}

Informar conflitos de interesse: financeiros, pessoais, entre possíveis revisores e editores, e/ou possíveis vieses temáticos. Se não houver, mencionar: Não se aplica. Para mais informações: https://www.abecbrasil.org.br/arquivos/whitepaper_CSE.pdf

Não se aplica 
LICENÇA DE USO - uso exclusivo da revista

Os autores cedem à Zero-a-Seis os direitos exclusivos de primeira publicação, com o trabalho simultaneamente licenciado sob a Licença Creative Commons Attribution (CC BY) 4.0 International. Esta licença permite que terceiros remixem, adaptem e criem a partir do trabalho publicado, atribuindo o devido crédito de autoria e publicação inicial neste periódico. Os autores têm autorização para assumir contratos adicionais separadamente, para distribuição não exclusiva da versão do trabalho publicada neste periódico (ex.: publicar em repositório institucional, em site pessoal, publicar uma tradução, ou como capítulo de livro), com reconhecimento de autoria e publicação inicial neste periódico.

PUBLISHER - uso exclusivo da revista

Universidade Federal de Santa Catarina. Núcleo de Estudos e Pesquisas da Educação na Pequena Infância - NUPEIN/CED/UFSC. Publicação no Portal de Periódicos UFSC. As ideias expressadas neste artigo são de responsabilidade de seus autores, não representando, necessariamente, a opinião dos editores ou da universidade.

EDITORES - uso exclusivo da revista Márcia Buss-Simão e Kátia Agostinho.

HISTÓRICO - uso exclusivo da revista

Recebido em: 23-11-2020 - Aprovado em: 01-12-2020 